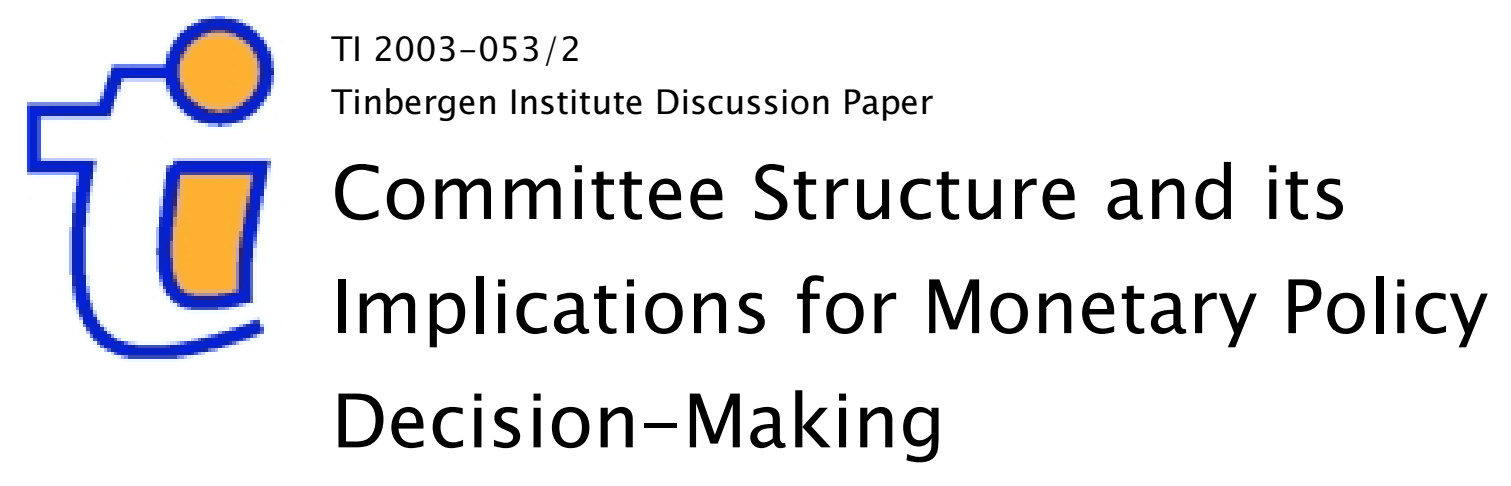

Jan Marc Berk $1,2,3$

Beata K. Bierut1,3,4

' De Nederlandsche Bank,

2 Faculty of Economics and Business Administration, Vrije Universiteit Amsterdam,

3 Tinbergen Institute

4 Faculty of Economics, Erasmus University Rotterdam. 


\section{Tinbergen Institute}

The Tinbergen Institute is the institute for economic research of the Erasmus Universiteit Rotterdam, Universiteit van Amsterdam, and Vrije Universiteit Amsterdam.

Tinbergen Institute Amsterdam

Roetersstraat 31

1018 WB Amsterdam

The Netherlands

Tel.: $\quad+31(0) 205513500$

Fax: $\quad+31(0) 205513555$

Tinbergen Institute Rotterdam

Burg. Oudlaan 50

3062 PA Rotterdam

The Netherlands

Tel.: $\quad+31(0) 104088900$

Fax: $\quad+31(0) 104089031$

Please send questions and/or remarks of nonscientific nature to driessen@tinbergen.nl.

Most TI discussion papers can be downloaded at http://www.tinbergen.nl. 


\title{
Committee structure and its implications for monetary policy decision-making
}

\author{
Jan Marc Berk*and Beata K. Bierut ${ }^{\ddagger}$ \\ July 7, 2003
}

\begin{abstract}
We investigate the implications for the setting of interest rates when monetary policy decisions are taken by a committee, in which a subset of members may meet prior to the voting in the committee and therefore has the possibility to reach consensus ex ante to vote unanimously ex post. We allow for different committee sizes, various voting rules and differences in skills among committee members. We find that the size of the committee is much less important in determining the degree of interest rate inertia than the skills of committee members. Moreover, prior interaction of a subgroup only has a minor effect on the setting of interest rates by the committee, provided that members on average are equally skilled and voting takes place using a simple majority rule. If either of those assumptions are relaxed, prior interaction has substantial effects on the setting of interest rates. In addition, prior interaction increases the optimal size of the Committee, ceteris paribus.
\end{abstract}

JEL codes: E52, E58

Key words: monetary policy, interest rates, voting

${ }^{*}$ De Nederlandsche Bank, Vrije Universiteit Amsterdam and Tinbergen Institute, the Netherlands.

${ }^{\dagger}$ De Nederlandsche Bank, Erasmus University Rotterdam and Tinbergen Institute, the Netherlands. Corresponding author. E-mail: B.K.Bierut@dnb.nl.

${ }^{\ddagger}$ The authors thank Job Swank, Otto Swank, Bauke Visser, Bryan Chapple and Henk van Kerkhoff for their invaluable help. The views expressed are those of the authors and need not represent the ones of the institutions affiliated. 


\section{Introduction}

Most textbooks on monetary policy are based, either implicitly or explicitly, on the assumption that policy decisions are taken by a homogenous entity, often denoted by 'the' central bank. However, in reality these decisions are the competence of a group of persons, organized in the form of a committee. Prominent examples include the Federal Open Market Committee (FOMC) of the Federal Reserve System and the Governing Council of the European Central Bank (ECB). As noted by, inter alia, Blinder (1998), the fact that monetary decision-making is conducted by a committee could have implications for the way policy is conducted. One could, for example, argue that committees tend to be inertial, as they tend to adopt compromise positions. In addition, members of monetary policy committees are often chosen to ensure a broad representation of society. This setup is often imbedded in a central bank structure characterized by a main office in a central location, with additional regional offices throughout the currency area. The US, where the Federal Reserve Act requires all of the monetary policy-makers to have some regional identity (see Meade and Sheets (2002)) again is a good example of such a 'hub-and-spokes' system. As a consequence, the FOMC consists of the members of the Board of Governors (hub) as well as the presidents of the Federal Reserve Banks (spokes). The Governing Council of the ECB includes members of the Executive Board of the ECB ('hub') as well as governors of all euro area national central banks ('spokes').

This paper investigates the implications for the setting of interest rates when decisions are taken by a 'hub-and-spokes' committee. Our main contribution to the literature is that we allow for a subset of members (the 'hub') to meet prior to the voting. This interaction may modify their behavior during the actual voting in the committee: they may for example ex ante decide to take an unanimous stand. ${ }^{1}$ When considering this issue, we allow for the possibility that committee members differ in the degree of accuracy in assessing the state of the economy. This asymmetry may (but need not) be related to an informational asymmetry. One could think of a situation in which the center produces, and disseminates only with some time lag, some statistical information, which is an important input in monetary policy discussions. The structure of the paper is as follows. After introducing, in the second section, the setup of our analysis we investigate in section 3 the accuracy of committee decision making under various voting rules, assuming that there is no systematic skill differential across members. Section 4

\footnotetext{
${ }^{1}$ In reality unanimous voting by a subset of the committee is rather common in monetary policy decision-making, see Gildea (1992). Whether this is the result of ex ante co-ordination remains to be seen, however.
} 
then extends this analysis to the case of asymmetric skills. We then turn, in section 5, to a discussion of the optimal size of the committee. Section 6 concludes.

Our results indicate that the possibility of prior interaction of a subgroup has a marginal effect on the interest rate set by the committee, provided members are on average equally skilled and committee decisions are taken by simple majority. Skill differentials and/or unanimity voting rule, however, imply that prior interaction has a substantial effect. Regarding the optimal size of the Committee, we by and large confirm the classic Condorcet result for our more complicated setting. In addition, the optimal size of the Committee is larger when the Board interacts prior to the Committee meeting.

\section{The setup}

We investigate interest rate decision-making by a committee of $n$ members which faces uncertainty about the prevailing economic conditions. We model this uncertainty by assuming that the economy can be in either of two states of the world: economic conditions may require a change of policy rates (state $A$ ) or not (state $B)$. Each of the states has a certain positive probability of occurring:

$$
\begin{aligned}
& P(A)=Q \\
& P(B)=1-Q
\end{aligned}
$$

The decision-making of the Committee is assumed also to be of a binary nature: the Committee has to decide whether interest rates should be changed (decision $A$ ) or not (decision $B$ ). The Committee decides only on monetary policy, and there is by assumption no intertemporal correlation of monetary policy outcomes. We also preclude strategic behavior.

Each individual member has a private opinion on the appropriate policy. The latter is based on private knowledge of current economic conditions (i.e. economic data becoming available after briefing by their staff, private conclusions drawn based on some (possibly common) information, etc.), which differs in the degree of accuracy. Therefore the probability that an individual assesses the current state of the world correctly (i.e. the probability of supporting the change of interest rates in state $A$ and opposing it in state $B)$ differs among Committee members:

$$
\begin{aligned}
& P_{i}(\operatorname{support} A \mid A)=P_{i}(\operatorname{support} B \mid B)=q_{i} \\
& P_{i}(\operatorname{support} B \mid A)=P_{i}(\operatorname{support} A \mid B)=1-q_{i}
\end{aligned}
$$


The $q_{i}$ 's represent individual decisional skills of Committee members. We assume furthermore that they represent independent draws from a single distribution with $E\left(q_{i, i \in N}\right)=q$. The latter may be interpreted as assuming that Committee members on average are equally skilled. This may be due to the fact that expertise often is an important selection criterion for membership. The Maastricht Treaty, for example, in this respect mentions "recognized standing and professional experience in monetary or banking matters" (Article 11). ${ }^{2}$

Throughout the paper we investigate the effects of interaction among Committee members on the accuracy of the decisions taken. The accuracy is measured by comparing the probability that the Committee takes a certain decision against the benchmark probabilities $Q$ and $1-Q$ as they represent the 'correct' level of monetary policy activism $(Q)$ or inertia $(1-Q)$. As to the decision rule used by the Committee to take the interest rate decision, we consider simple majority for the case in which members are equally skilled, and weighted majority for asymmetric skills. As explained in appendix 2, these are the optimal rules for both cases, provided certain conditions are fulfilled, see also Ben-Yashar and Nitzan (1997). We also consider unanimity, which is not optimal but is alleged to have empirical relevance.

We allow for various forms of interaction. We start by assuming that $m$ out of $n$ (exogenously selected) members (the Board) meet prior to voting in the Committee and exchange views on economic conditions. As a result the Board may decide to take an unanimous stand regarding the interest rate proposal formulated in the upcoming Committee meeting. The non-Board Committee members do not know what the position of the Board during the Committee vote, which is simultaneous, will be. The alternative consists of each Board member voting individually. We subsequently extend the scope of interaction by exploring the effects of an exchange of views among all Committee members, which may induce some of the non-Board Committee members to follow the position of the Board. In all cases we assume that interest rates are kept unchanged if at least $k$ Committee members are against the change (they support $B$ ).

We assume that, depending on the distribution of opinions among Board members; the meeting of Board members can generate three outcomes: if there is a majority in the Board in favour of either decision, the Board adopts the majority view, otherwise Board members will vote individually in the Committee meeting. Our assumed decision rule for the Board introduces an endogenous possibility that the Board does not reach any prior decision. ${ }^{3}$

\footnotetext{
${ }^{2}$ For that reason, in what follows we will restrict our attention to results for individual decisional skills not lower than 0.5 .

${ }^{3}$ Let us assume that $m=6$ and $k_{B}=5$. If 4 members are for a change in interest rates
} 
The latter is relevant, as the formal decision on interest rates is taken in the Committee only. The Board thus has the possibility to decide 'not to decide'.

The corresponding probabilities associated with each outcome: consensus for a change in interest rates $(C(A))$, consensus for status quo $(C(B))$ or individual decision $(I)$ depend on the likelihood of the state of the world occurring and decisional skills of the Board members:

$$
\begin{aligned}
P(C(B)) & =Q \sum_{\substack{S \subset M \\
s \geq k_{B}}} \prod_{i \in S}\left(1-q_{i}\right) \prod_{i \notin S} q_{i}+(1-Q) \sum_{\substack{S \subset M \\
s \geq k_{B}}} \prod_{i \in S} q_{i} \prod_{i \notin S}\left(1-q_{i}\right)(1) \\
P(C(A)) & =Q \sum_{\substack{S \subset M \\
s \geq k_{B}}} \prod_{i \in S} q_{i} \prod_{i \notin S}\left(1-q_{i}\right)+(1-Q) \sum_{\substack{S \subset M \\
s \geq k_{B}}} \prod_{i \in S}\left(1-q_{i}\right) \prod_{i \notin S} q_{i}(2) \\
P(I) & =1-P(C)=1-P(C(B))-P(C(A))
\end{aligned}
$$

where the sums are taken over all subsets $S$ of the set of the Board members $M=\{1,2,3, \ldots, m\}$, such that $s$ (the number of members in $S$ ) is at least $k_{B}$.

Under the assumption that individual decisional skills of the Board members represent independent draws from a single distribution with $E\left(q_{i, i \in M}\right)=$ $q_{B}$, average (expected) probabilities of the Board taking either of the three actions are given as:

$$
\begin{aligned}
E P(C(B)) & =Q \sum_{s=k_{B}}^{m}\left(\begin{array}{c}
m \\
s
\end{array}\right)\left(1-q_{B}\right)^{s} q_{B}^{m-s}+(1-Q) \sum_{s=k_{B}}^{m}\left(\begin{array}{c}
m \\
s
\end{array}\right) q_{B}^{s}\left(1-q_{B}\right)^{m}\left(4^{s}\right) \\
E P(C(A)) & =Q \sum_{s=k_{B}}^{m}\left(\begin{array}{c}
m \\
s
\end{array}\right)\left(1-q_{B}\right)^{m-s} q_{B}^{s}+(1-Q) \sum_{s=k_{B}}^{m}\left(\begin{array}{c}
m \\
s
\end{array}\right) q_{B}^{m-s}\left(1-q_{B}\left(5^{s}\right)\right. \\
E P(I) & =1-E P(C)=1-[E P(C(B))+E P(C(A))]
\end{aligned}
$$

Figure 1 presents graphically the expected probability that a 6-member Board assumes a common position in the Committee (i.e. collectively supports either a proposal to change interest rates or to leave them unchanged) as a function of average decisional skills of its members for two limiting cases: the maximum threshold (or unanimity, $k_{B}=6$ ) ${ }^{4}$ and the minimum threshold $\left(k_{B}=4\right)^{5}$.

and 2 for status quo, then the Board would not reach a common position. If the opinions were divided 5 to 1 , then the Board would unanimously support the change in interest rates.

${ }^{4}$ Thicker line

${ }^{5}$ Thinner line 


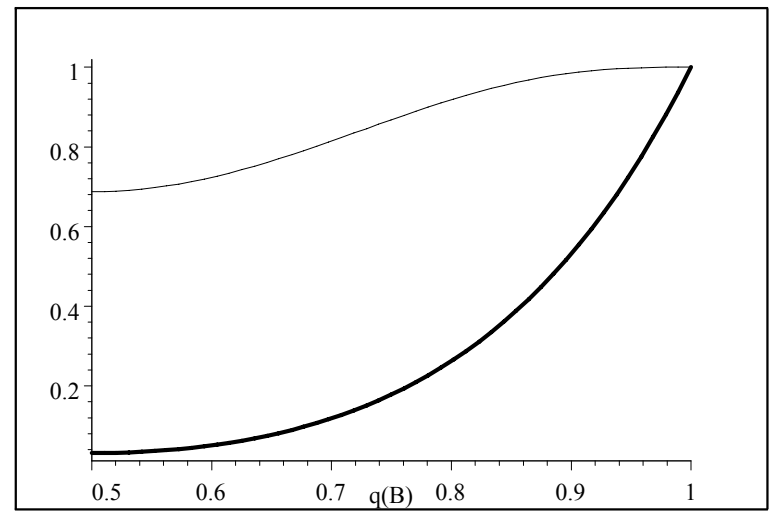

Figure 1: Expected probability that the Board will reach consensus

The Board is more likely to reach consensus if average decisional skills of its members are higher, since then each Board member is increasingly likely to assess the state of the economy correctly. The likelihood of achieving a consensual outcome depends also on the adopted decision rule: it varies considerably under unanimity rule (i.e. $k_{B}=6$ ) and remains consistently high under majority rule (i.e. $k_{B}=4$ ).

An alternative would be to assume that the Board always reaches a common position. In that case the decision rule adopted by the Board is ordinary simple majority and the probabilities (4)-(6) should be expressed as follows:

$$
\begin{aligned}
\widetilde{E P}(C(B)) & =Q \sum_{s=4}^{6}\left(\begin{array}{l}
6 \\
s
\end{array}\right)(1-q)^{s} q^{6-s}+(1-Q) \sum_{s=4}^{6}\left(\begin{array}{l}
6 \\
s
\end{array}\right) q^{s}(1-q)^{6-s}(7) \\
\widetilde{E P}(C(A)) & =1-\widetilde{P}(C(B)) \\
\widetilde{E P}(I) & =0
\end{aligned}
$$

It turns out (see appendix 1) that this decision rule is inferior in terms of quality of decision-making of the Committee when compared to the rule described above. This is because simple majority leads to a less efficient use of Board members' expertise (or information). This finding, combined with the results of Meade and Sheets (2002) regarding actual FOMC voting behavior that document existing dissents among members of the Board, in our view justifies our choice of the Board's decision rule. 


\section{Voting on interest rates without a skill bias}

\subsection{Individual voting}

If the Board does not interact prior to the Committee meeting, the decisiontaking situation represents a standard voting game. ${ }^{6}$ The probabilities of passing the decision in favour of status quo (decision $B$ ) or in favour of a change in interest rates (decision $A$ ) by the Committee under a simple majority rule are:

$$
\begin{aligned}
& P^{I N D}(\operatorname{decision} B)=Q \sum_{\substack{S \subset N \\
s \geq \frac{n+1}{2}}} \prod_{i \in S}\left(1-q_{i}\right) \prod_{i \notin S} q_{i}+(1-Q) \sum_{\substack{S \subset N \\
s \geq \frac{n+1}{2}}} \prod_{i \in S} q_{i} \prod_{i \notin S}(1-(\text { dy } q)) \\
& P^{I N D}(\operatorname{decision} A)=1-P^{I N D}(\text { decision } B)
\end{aligned}
$$

where $N=\{1,2,3, \ldots, n\}$ is the set of all Committee members (i.e. including the members of the Board).

The expected probabilities of passing either of the two decisions in the Committee are related to average decisional skills of Committee members, $E\left(q_{i, i \in N}\right)=q$ :

$\left.E P^{I N D}(\operatorname{decision} B)=Q \sum_{s=\frac{n+1}{2}}^{n}\left(\begin{array}{l}n \\ s\end{array}\right)(1-q)^{s} q^{n-s}+(1-Q) \sum_{s=\frac{n+1}{2}}^{n}\left(\begin{array}{l}n \\ s\end{array}\right) q^{s}(1-q)()^{m}\right)$ $E P^{I N D}(\operatorname{decision} A)=1-E P^{I N D}(\operatorname{decision} B)$

The interpretation of these probabilities is quite intuitive. If the prior probability indicates that the economic situation more likely does (does not) require a change in interest rates (i.e. if $Q>(<) 0.5$ ), the average probability of passing a change (decision $A$ ) is increasing (decreasing) in the average level of decisional skills. In other words, the Committee composed of better-skilled (or better-informed) individuals is more likely to agree on the appropriate action than the Committee composed of less-skilled members. If both states of the world are equally likely $(Q=0.5)$, then the expected probability that either decision is taken is independent of the Committee size and average decisional skills and is equal to $50 \%$.

Figures 2 and 3 depict graphically expected probabilities of a change in interest rates (decision $A$ ) for $Q=0.25$ and $Q=0.75$ for different Committee sizes, i.e. $n=\{9,19,29\}$. Throughout the paper, thicker lines indicate higher $n$.

\footnotetext{
${ }^{6}$ See e.g. Austen-Smith and Banks (1996), Ben-Yashar and Nitzan (1997) or Nitzan and Paroush (1985)
} 


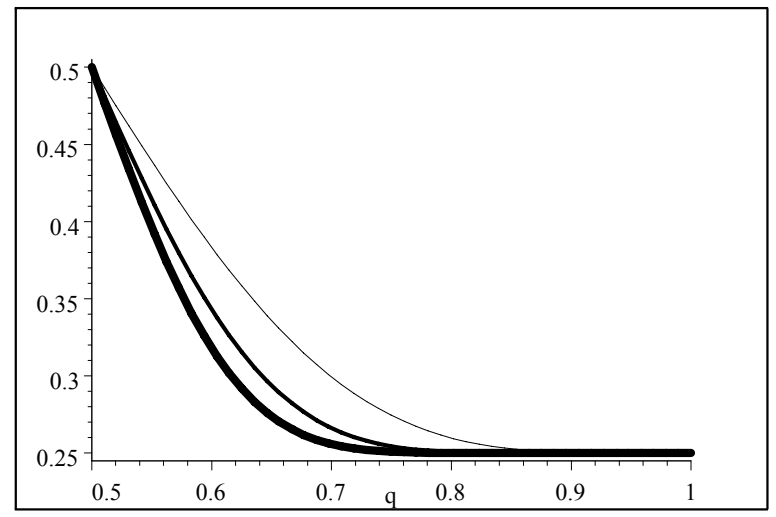

Figure 2: Expected probability that the Committee will change interest rates if $Q=0.25$ (individual voting)

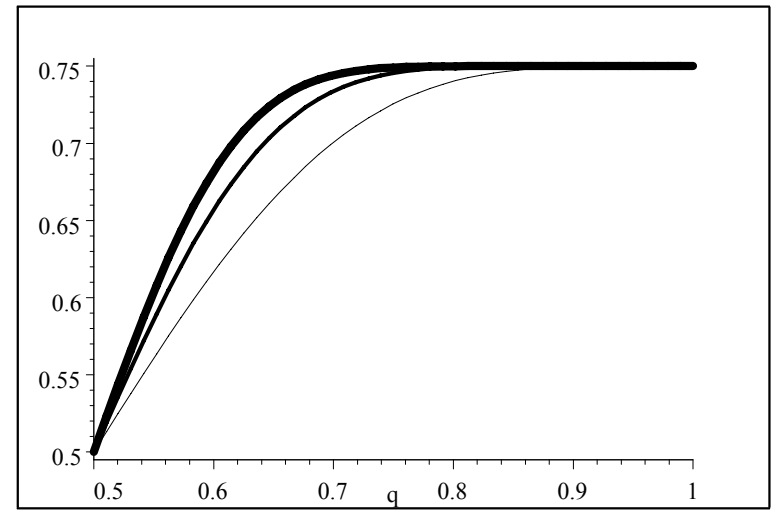

Figure 3: Expected probability that the Committee will change interest rates if $Q=0.75$ (individual voting)

We start with an explanation of the asymptotics. As decisional skills approach perfection (i.e. as $q$ approaches unity), on average every Committee member is able to assess the economic conditions correctly. Therefore the expected probability that the Committee will take a certain decision converges to the prior probability that the state of the world requires such an action. As $q$ approaches 0.5 , the decision-making of each member is comparable to tossing a coin, therefore both outcomes of Committee meeting become equally likely. ${ }^{7}$

Furthermore, the likelihood of a change in interest rates does not vary substantially with the actual size of the Committee. That is, increasing the size of the Committee does not necessarily increase the degree of interest rate inertia or activism substantially. However, for given average decisional

\footnotetext{
${ }^{7}$ If $q$ approaches zero, average decisional skills in the Committee would be so low, that the Committee is increasingly likely to take a decision that is at odds with the state of the world.
} 
skills, the speed of convergence to the prior probability increases with the size of the Committee. In other words, the size of the Committee influences the relevance of individual decisional skills, in that this influence diminishes with the Committee size.

\section{$3.2 \quad$ Interdependent voting}

We now investigate the effects of prior interaction, first limiting ourselves to the case of discussion among Board members alone. Under the decision rule for the Board as represented by (4)-(6) the total probabilities that the Committee will change interest rates or not are:

$$
\begin{aligned}
P(\text { decision } B)= & P(\text { decision } B \mid I) P(I)+P(\text { decision } B \mid C(A)) P(C(A)) \\
& +P(\text { decision } B \mid C(B)) P(C(B)) \\
P(\text { decision } A)= & 1-P(\text { decision } B)
\end{aligned}
$$

The probabilities $P(I), P(C(A))$ and $P(C(B))$ are defined in the previous section. We need to define the conditional probabilities that the Committee takes a certain decision in each of the three cases.

If during the Board's meeting opinions are divided and there is no consensual outcome, members of the Board will vote individually in the Committee, ex hypothesi expressing the same opinion as voiced in the Board meeting. Therefore between $m-k_{B}+1$ and $k_{B}-1$ members will vote for a change in interest rates and the rest of the Board members will vote against. This is important for calculating how many non-Board members have to be in favour of the certain alternative in order to get it passed by simple majority. In particular, if $k_{B}=4$, then Board members will vote individually ex post only in the case when 3 members are for a change in interest rates and 3 are against. Therefore the Committee will adopt a change in interest rates if at least $\frac{n+1}{2}-3$ non-Board members will vote for a change. The reasoning is quite similar if the Board adopts a common position. Obtaining the majority for one alternative, in the case of the Board voting against it, requires the majority of $\frac{n+1}{2}$ non-Board members to be in favour. If the Board votes in favour of this alternative, then only $\frac{n+1}{2}-m$ non-Board members have to be of the same opinion. Therefore, for $m=6$ and $k_{B}=4$ we have:

$P($ decision $B \mid I)=Q \sum_{\substack{S \subset N-M \\ s \geq \frac{n+1}{2}-3}} \prod_{i \in S}\left(1-q_{i}\right) \prod_{i \notin S} q_{i}+(1-Q) \sum_{\substack{S \subset N-M \\ s \geq \frac{n+1}{2}-3}} \prod_{i \in S} q_{i} \prod_{i \notin S}\left(1-q_{i}\right)$ 


$$
\begin{aligned}
& P(\text { decision } B \mid C(A))=Q\left\{\sum_{\substack{S \subset N-M \\
s \geq \frac{n+1}{2}}}^{0 \text { if } n \leq 11} \prod_{i \in S}\left(1-q_{i}\right) \prod_{i \notin S} q_{i} \text { if not }\right\} \\
& +(1-Q)\left\{\begin{array}{c}
0 \text { if } n \leq 11 \\
\left.\underset{\substack{S \subset N-M \\
s \geq \frac{n+1}{2}}}{ } \prod_{i \in S} q_{i} \prod_{i \notin S}\left(1-q_{i}\right) \text { if nott } 17\right\}
\end{array}\right. \\
& P(\text { decision } B \mid C(B))=Q\left\{\sum_{\substack{S \subset N-M \\
s \geq \frac{n+1}{2}-6}}^{1 \text { if } n \leq 11} \prod_{i \in S}\left(1-q_{i}\right) \prod_{i \notin S} q_{i} \text { if not }\right\} \\
& +(1-Q)\left\{\begin{array}{c}
1 \text { if } n \leq 11 \\
\left.\sum_{\substack{S \subset N-M \\
s \geq \frac{n+1}{2}-6}} \prod_{i \in S} q_{i} \prod_{i \notin S}\left(1-q_{i}\right) \text { if nott } 18\right\}
\end{array}\right.
\end{aligned}
$$

We can now compute the total probabilities of a change (decision $A$ ) or no change (decision $B$ ) in interest rates. Assuming again that decisional skills are independently distributed, we can express expected probabilities of either outcome as a function of average decisional skills of the Board members and all Committee members:

$E P($ decision $B)=E P($ decision $B \mid I) E P(I)+E P($ decision $B \mid C(A)) E P(C(A))$

$$
+E P(\text { decision } B \mid C(B)) E P(C(B))
$$

$E P(\operatorname{decision} A)=1-E P(\operatorname{decision} B)$

where the expected conditional probabilities can be expressed as:

$$
\begin{gathered}
E P(\text { decision } B \mid I)=Q \sum_{s=\frac{n+1}{2}-3}^{n-6}\left(\begin{array}{c}
n-6 \\
s
\end{array}\right)(1-q)^{s} q^{n-6-s} \\
+(1-Q) \sum_{s=\frac{n+1}{2}-3}^{n-6}\left(\begin{array}{c}
n-6 \\
s
\end{array}\right) q^{s}(1-q)^{n-6-s} \quad(21) \\
E P(\text { decision } B \mid C(A))=\left\{\begin{array}{l}
Q \sum_{s=\frac{n+1}{2}}^{n-6}\left(\begin{array}{c}
n-6 \\
s
\end{array}\right)(1-q)^{s} q^{n-6-s} \\
+(1-Q) \sum_{s=\frac{n+1}{2}}^{n-6}\left(\begin{array}{c}
n-6 \\
s
\end{array}\right) q^{s}(1-q)^{n-6-s} \text { if not }
\end{array}\right\} \\
E P(\text { decision } B \mid C(B))=\left\{\begin{array}{c}
Q \sum_{s=\frac{n+1}{2}-6}^{n}\left(\begin{array}{c}
n-6 \\
s
\end{array}\right)(1-q)^{s} q^{n-6-s} \\
+(1-Q) \sum_{s=\frac{n+1}{2}-6}^{n-6}\left(\begin{array}{c}
n-6 \\
s
\end{array}\right) q^{s}(1-q)^{n-6-s} \text { if not } n
\end{array}\right.
\end{gathered}
$$


Figures 4 and 5 depict graphically the expected likelihood of the Committee deciding on a change in interest rates, conditional on the Board interacting (solid lines), as a function of average decisional skills in the Committee, q. Given the large number of parameters involved, we present expected probabilities for two priors, $Q=\{0.25,0.75\}^{8}$, and two Committee sizes, $n=\{9,19\}, m=6$ and $k_{B}=4$. Dotted lines refer to the case in which the Board has no option to meet prior to the interest rate voting and can be traced back to figures 2 and 3 .

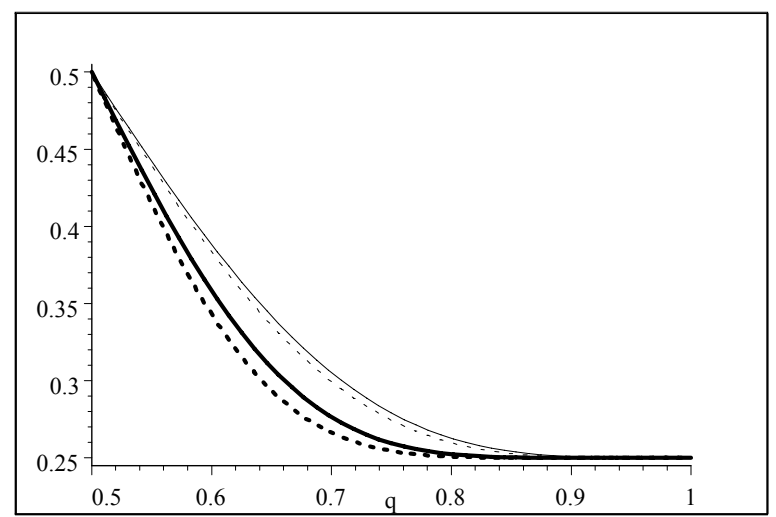

Figure 4: Expected probability that the Committee will change interest rates $(Q=0.25)$

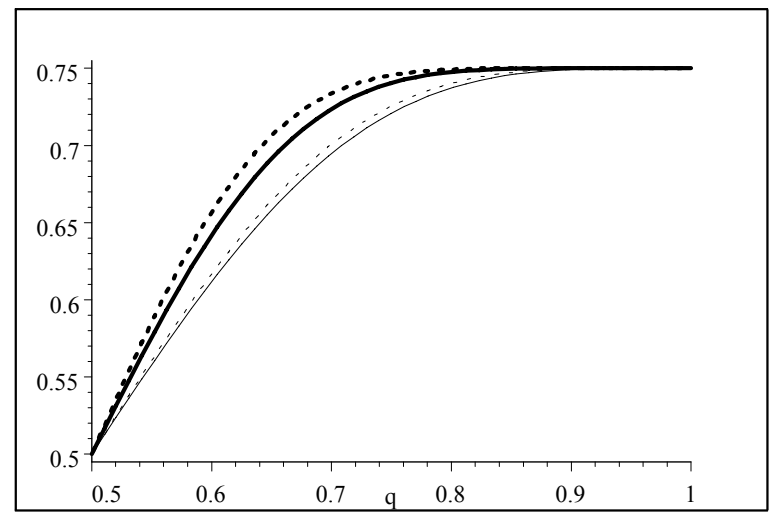

Figure 5: Expected probability that the Committee will change interest rates $(Q=0.75)$

It follows from these graphs that prior interaction of the Board members has a minor but consistently negative effect in terms of the quality of the Committee's decision-making: assuming a common position implies that

\footnotetext{
${ }^{8}$ For $Q=0.5$ expected probabilities of taking either decision are equal, i.e. $E P$ (decision $B)=E P(\operatorname{decision} A)=0.5$, regardless whether the Board members do or do not decide ex ante to take an unanimous position ex post.
} 
some private expertise (information) is ignored, which reduces the accuracy of the common decision. Further interpretation is similar to the conclusions presented earlier: Committee's size does not seem to be very relevant in determining the likelihood of a change in interest rates. The skills of Committee members are very relevant in this context, as poor skills lead to an increased likelihood that the Committee takes a wrong decision.

We now extend the scope of interaction within the Committee beyond the Board members, by assuming that this results in some of the non-Board Committee members deciding to follow the position of the Board. This obviously is conditional on the Board reaching consensus. Furthermore, it requires that the Board's position is revealed prior to the vote on interest rates. ${ }^{9}$ More specifically, the probability that the influenceable Committee member $i$ is in favour of a certain alternative reads as follows:

$$
\begin{aligned}
& \left.\widetilde{P}_{i}(\text { support } A)=\left\{\begin{array}{c}
1 \text { if the Board supports } A \\
0 \text { if the Board is supports } B \\
P_{i}(\text { support } A) \text { if the Board votes individually }
\end{array}\right\} 24\right) \\
& \left.\widetilde{P}_{i}(\text { support } B)=\left\{\begin{array}{c}
1 \text { if the Board is supports } B \\
0 \text { if the Board is supports } A \\
P_{i}(\text { support } B) \text { if the Board votes individually }
\end{array}\right\} 25\right)
\end{aligned}
$$

where the probabilities $P_{i}(\operatorname{support} A)$ and $P_{i}(\operatorname{support} B)$ correspond to individual decisional skills of member $i$ as defined in section 2 .

The dependence in decision-making affects the conditional probabilities in the cases when the Board has a common position. If we assume that the number of influenceable Committee members is $d, d \in D \subset(N-M)$, expressions (22) and (23) become:

$E P($ decision $B \mid C(A))=\left\{\begin{array}{c}0 \text { if } n \leq 11+2 d \\ Q \sum_{s=\frac{n+1}{2}}^{n-6-d}\left(\begin{array}{c}n-6-d \\ s\end{array}\right)(1-q)^{s} q^{n-6-d-s} \\ +(1-Q) \sum_{s=\frac{n+1}{2}}^{n-6-d}\left(\begin{array}{c}n-6-d \\ s\end{array}\right) q^{s}(1-q)^{n-6-d-s} \text { if not }\end{array}\right\}$

\footnotetext{
${ }^{9}$ We continue to use simple majority as the voting rule of the Committee. Note however, that this rule is likely not to be optimal when interaction is extended beyond the Board, even when skills are equal on average. We plan to take up this issue in subsequent research.
} 
$E P($ decision $B \mid C(B))=\left\{\begin{array}{c}1 \text { if } n \leq 11+2 d \\ Q \sum_{s=\frac{n+1}{2}-6-d}^{n-6-d}\left(\begin{array}{c}n-6-d \\ s\end{array}\right)(1-q)^{s} q^{n-6-d-s} \\ +(1-Q) \sum_{s=\frac{n+1}{2}-6-d}^{n-6-d}\left(\begin{array}{c}n-6-d \\ s\end{array}\right) q^{s}(1-q)^{n-6-d-s} \text { if not }\end{array}\right\}$

As the number of influenceable Committee members $d$ increases, the Board becomes more and more dominant. Even if the number of the Board members is small, if $d$ exceeds $\left(\frac{n-1}{2}-6\right)$ the Board effectively has majority in the Committee. The effect on the accuracy of Committee decisions is negative: since each member is more likely to be correct than not (i.e. $q_{i} \geq 0.5$ ), foregoing the expertise of every single individual is damaging for the collective outcome.

Figures 6 and 7 depict graphically the expected likelihood that the 19member Committee decides to change interest rates in all three cases: no interaction (dotted lines), interaction among Board members only (solid lines) and interaction in the whole Committee (dashed lines). In the latter case we assume that 3 non-Board Committee members are susceptible to the argumentation of the Board. The lines depicting the behavior of the Committee of 9 members are omitted since, as the Board already has the majority in this Committee, strengthening the Board's position further has no additional effects.

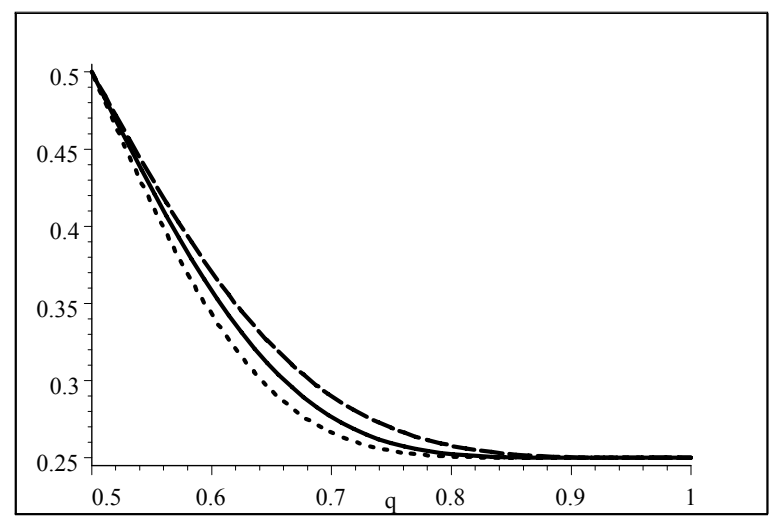

Figure 6: Expected probability that the Committee will change interest rates $(Q=0.25)$ 


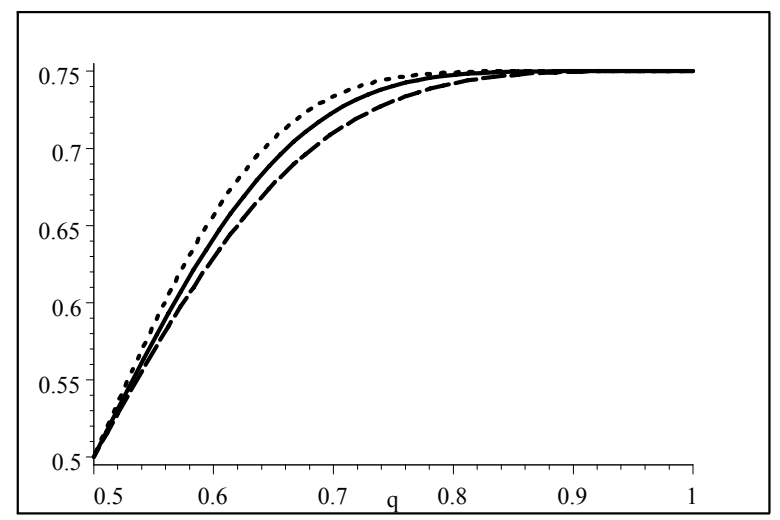

Figure 7: Expected probability that the Committee will change interest rates $(Q=0.75)$

We conclude that broadening the scope of interaction reduces convergence of the probability that the Committee takes a certain decision to the true probability. This result is in line with the literature: "...the employment of the optimal decision rule [simple majority in our case], given independent voting, is superior to using the same rule when decisions are interrelated..." (Nitzan and Paroush, 1985).

\subsection{Unanimity}

Our investigation of unanimity $(k=n)$ as the voting rule for the Committee assumes that the default option is status quo and that interest rates are changed only if Committee members unanimously vote against the proposal of keeping rates unchanged. Therefore the probabilities of a change in interest rates (decision $A$ ) read as follows:

$$
P^{I N D}(\operatorname{decision} A)=Q \prod_{i \in N} q_{i}+(1-Q) \prod_{i \in N}\left(1-q_{i}\right)
$$

if there is no interaction in the Committee and

$$
\begin{aligned}
P(\operatorname{decision} A)= & Q\left(\sum_{\substack{S \subset M \\
s \geq 4}} \prod_{i \in S} q_{i} \prod_{i \notin S}\left(1-q_{i}\right)\right) \prod_{i \in N-M-D} q_{i} \\
& +(1-Q)\left(\sum_{\substack{S \subset M \\
s \geq 4}} \prod_{i \in S}\left(1-q_{i}\right) \prod_{i \notin S} q_{i}\right) \prod_{i \in N-M-D}(1-q(\& 9)
\end{aligned}
$$

in the case of interaction (restricting interaction solely to Board members implies that the set $D$ of influenceable non-Board Committee members is 
empty). The expected probabilities (computed under the assumptions $m=6$ and $\left.k_{B}=4\right)$ are given as:

$$
\begin{aligned}
E P^{I N D}(\operatorname{decision} A)= & Q q^{n}+(1-Q)(1-q)^{n} \\
E P(\operatorname{decision} A)= & Q\left(\sum_{s=4}^{6}\left(\begin{array}{l}
6 \\
s
\end{array}\right) q^{s}(1-q)^{6-s}\right) q^{n-6-d} \\
& +(1-Q)\left(\sum_{s=4}^{6}\left(\begin{array}{l}
6 \\
s
\end{array}\right) q^{6-s}(1-q)^{s}\right)(1-q)^{n-6}(32)
\end{aligned}
$$

Figures 8, 9 and 10 present expected probabilities of a change in interest rates under an unanimous voting rule for two Committee sizes: $n=\{9,19\}$ and three priors: $Q=\{0.25,0.5,0.75\}$. As before, the dotted line refers to the case of no interaction, solid lines to the case when the Board interacts and dashed lines to interaction among all Committee members. Again we assume that 3 non-Board Committee members follow the position of the Board. In the case of the smaller Committee this implies that the Board is able to convince all other Committee members of its position, so that the probability that the Committee will change interest rates is equal to the probability that the Board will reach consensus in favour of the change: $E P(\operatorname{decision} A)=E P(C(A))$.

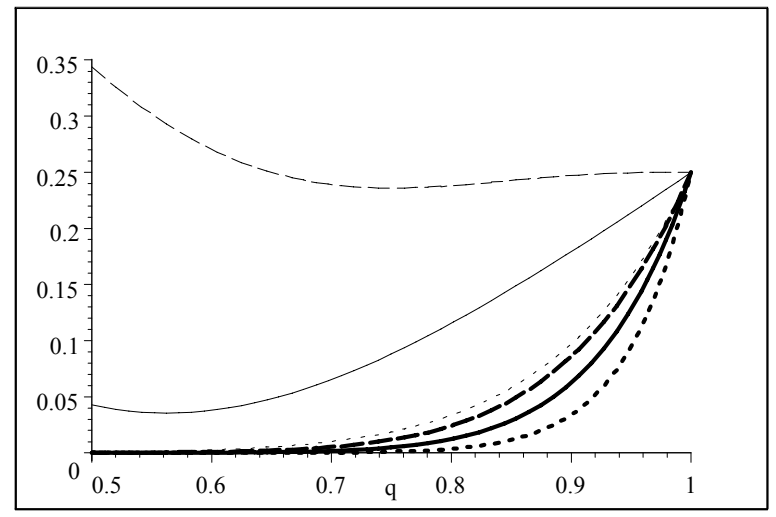

Figure 8: Expected probability of interest rate change under unanimity

$$
(Q=0.25)
$$




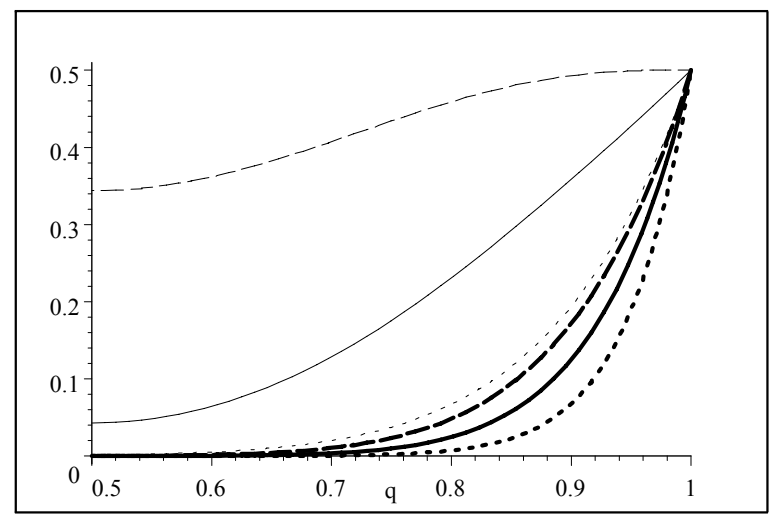

Figure 9: Expected probability of interest rate change under unanimity $(Q=0.5)$

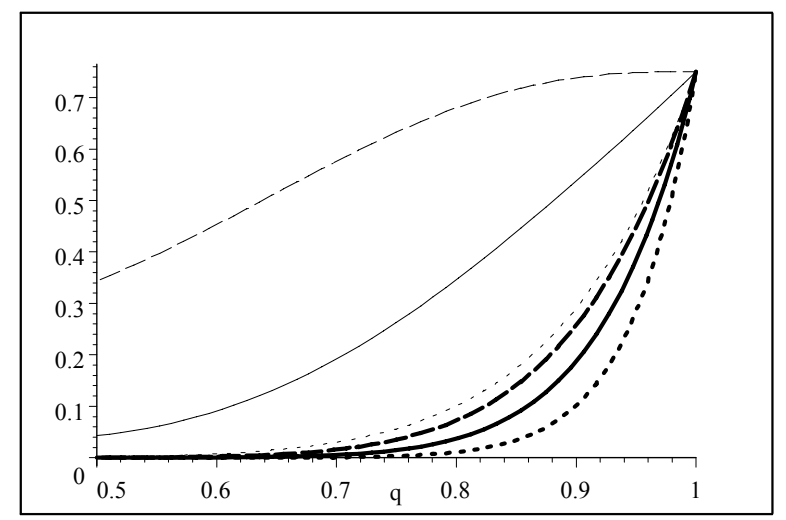

Figure 10: Expected probability of interest rate change under unanimity $(Q=0.75)$

The figures corroborate the largely qualitative statements made by Blinder (1998), as quoted in the introduction. If the Committee has preference for unanimous decision-making, the degree of monetary policy activism will be close to zero (especially if the Committee is relatively large). The probability of changing interest rates converges to the true probability $Q$ only for high levels of decisional skills $q$. Interaction increases the probability that interest rates will be changed. This is because it 'softens' the rigidity inherent in the unanimous voting rule, i.e. the requirement that all members must be of the same opinion. If the Board is allowed to decide on its common position, the actual number of Committee members which have to be in favour of a change in interest rates is $n-m+k_{B}$ and not $n$ (since $m-k_{B}$ members of the Board will vote for a change against their private opinion). If the Board is allowed to share its views with other Committee members and is able to convince some of them, the number of extra Committee members which have to be in favour of a change in interest rates is further reduced 
to $n-m-d+k_{B}$. The impact of interaction is larger, ceteris paribus, for: (1) smaller Committees, (2) larger number of influenceable Committee members. Interestingly enough, if the Board is able to convince all Committee members of its position, the degree of Committee's activism can even exceed the true probability $Q$.

\section{Implications of a systematic skill differen- tial}

In this section we will make our structure more complex by assuming that the decisional skills of Board members are on average higher than those of (non-Board) Committee members, i.e. $q_{B}>q_{N B}$. This systematic skill differential between the 'hub' and the 'spokes' may for example be due to an informational advantage. ${ }^{10}$ The optimal decision rule in this case would be weighted majority, with higher weights assigned to better-skilled individuals (see Ben-Yashar and Nitzan (1997), see also appendix 2). However, in order to allow a comparison with the previous section we start with simple majority. The latter also turns out to be a reasonable approximation of the optimal rule, especially when the Committee is relatively small and/or decisional skills are high (see appendix 2).

\subsection{Simple majority}

Figures 11 and 12 represent expected probabilities of an interest rate change for $q_{B}=0.8$ as a function of average decisional skills of the non-Board members of the Committee, $q_{N B}\left(Q=\{0.25,0.75\}^{11}, n=\{9,19\}, m=6\right.$, $\left.k_{B}=4\right)$. The key to the lines remains unchanged. ${ }^{12}$

\footnotetext{
${ }^{10}$ Assuming $q_{N B}>q_{B}$ would reverse the results.

${ }^{11}$ When the prior is neutral, i.e. $Q=0.5$, the likelihood of a change in interest rates is fixed at $50 \%$.

${ }^{12}$ I.e. dotted lines correspond to the no-interaction case, solid lines to interaction limited to Board members and dashed lines to interaction in the whole Committee.
} 


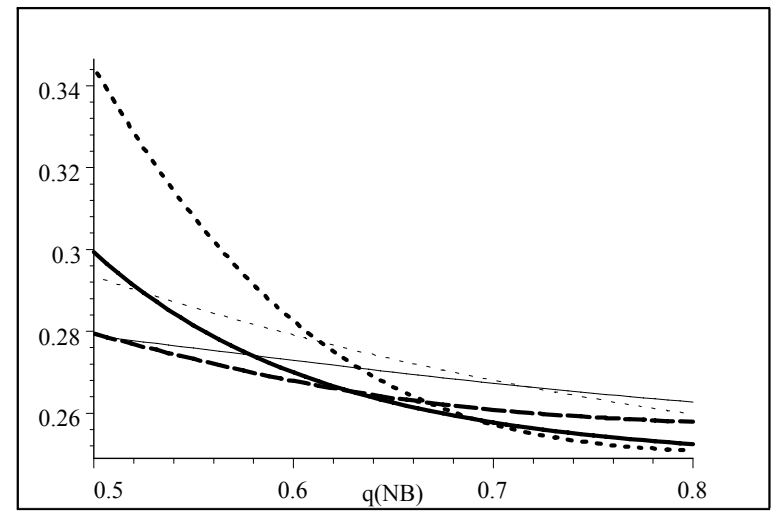

Figure 11: Expected probability that the Committee will change interest rates if $Q=0.25\left(q_{N B}<q_{B}=0.8\right)$

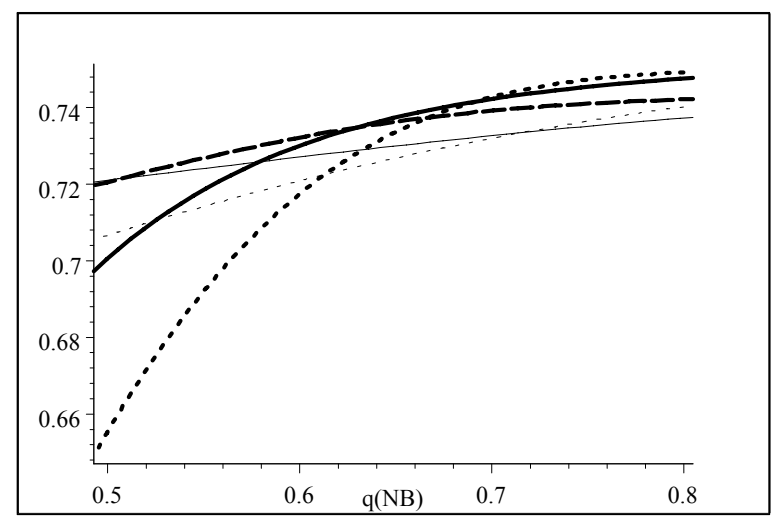

Figure 12: Expected probability that the Committee will change interest rates if $Q=0.75\left(q_{N B}<q_{B}=0.8\right)$

The fact that Board members are (on average) more accurate in their decisions modifies the conclusions from the previous section. Whereas we concluded in the latter that the possibility of the Board reaching consensus a priori did not have a major influence, we now see that allowing prior interaction among Board members may improve the accuracy of the decision making process (although if the skills of the non-Board members exceed a certain threshold individual voting is superior):

- if the Committee is small, such that the Board has a majority in the Committee, the expected probability of a change in interest rates differs by at most 3 percentage points from the true probability $Q$ in the case of interaction, compared to 5 percentage points if interaction is precluded

- in a large Committee, this effect is even more profound: the difference is reduced from 10 to 3 percentage points (if interaction is extended to the whole Committee). ${ }^{13}$

\footnotetext{
${ }^{13}$ If the asymmetry in skills was opposite, i.e. if Board members were relatively less
} 


\subsection{Weighted voting}

An alternative voting rule for decision making in the Committee is based on a weighting of votes of individual members according to individual expertise. Throughout this subsection we will use optimal weights as explained in appendix 2 (in particular, equations (49) and (50)).

Figures 13 and 14 correspond to figures in the previous subsection and present expected probabilities that the 19-member Committee decides to change interest rates if the votes are weighted.

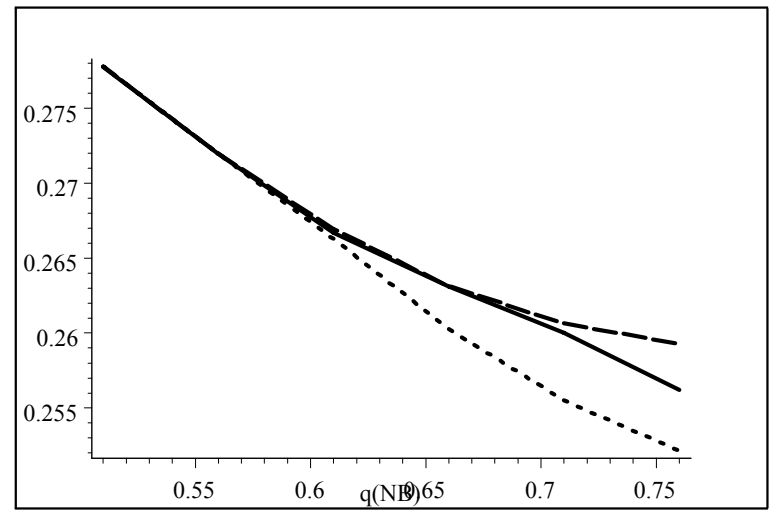

Figure 13: Expected probability that the Committee will change interest rates if the votes are weighted $(Q=0.25)$

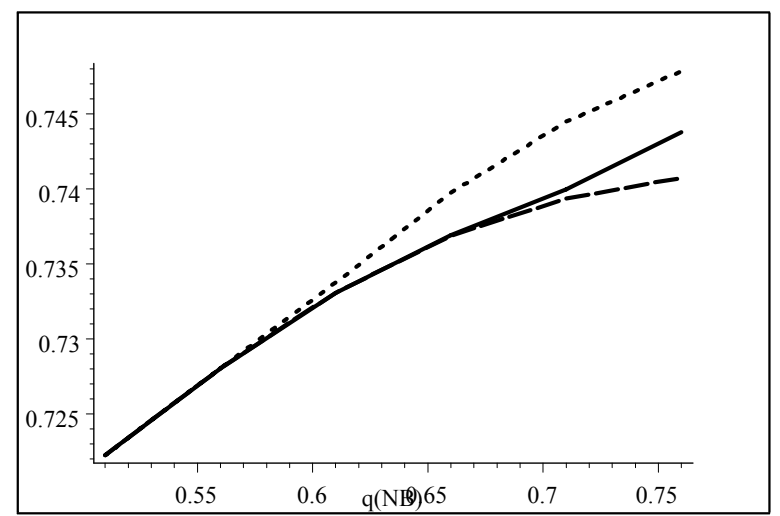

Figure 14: Expected probability that the Committee will change interest rates if the votes are weighted $(Q=0.75)$

As in the case of simple majority voting under symmetric skills, allowing for interaction among the members of the Committee in the case when

skilled, the conclusions should be reversed: prior interaction of Board members would reduce the accuracy of the decisions of the Committee. However, this effect becomes less relevant the larger the Committee (provided it is dominated by the non-Board members). 
their skills are asymmetric and therefore their votes are weighted reduces the accuracy of the decisions (although assigning the optimal weights to the votes improves the accuracy). Therefore we can again conclude that, if the optimal decision rule is implemented, interaction can only hamper the decision-making process. However, if the decision rule is not optimal (e.g. if the decisional skills are asymmetric but the votes are not weighted), allowing for interaction can be beneficial, especially if interaction is allowed among more skilled individuals (the Board in our case). Interaction reinforces the position of the Board and may effectively replace the optimal voting rule.

\subsection{Unanimity}

We now consider the expected probability that the Committee will change interest rates in the case when the decision has to be taken by unanimity. The expected probabilities that the Committee will adopt a change in cases when interaction is allowed and not are given as follows:

$$
\begin{aligned}
E P(\operatorname{decision} A)= & Q\left(\sum_{s=4}^{6}\left(\begin{array}{l}
6 \\
s
\end{array}\right) q_{B}^{s}\left(1-q_{B}\right)^{6-s}\right) q_{N B}^{n-6-d} \\
& \left.+(1-Q)\left(\sum_{s=4}^{6}\left(\begin{array}{l}
6 \\
s
\end{array}\right) q_{B}^{6-s}\left(1-q_{B}\right)^{s}\right)\left(1-q_{N B}\right)^{n-\left(33^{6}\right.}\right) \\
E P^{I N D}(\operatorname{decision} A)= & Q q_{B}^{6} q_{N B}^{n-6}+(1-Q)\left(1-q_{B}\right)^{6}\left(1-q_{N B}\right)^{n-6}
\end{aligned}
$$

In this case, we reverse the earlier findings that asymmetric skills are necessary to generate substantial effects of prior interaction on Committee decision making, when we assumed that decisions are taken by simple majority. Below we present figures 15, 16 and 17 depicting expected probabilities of a change in interest rates in the case of asymmetric skills $\left(q_{B}=0.8, q_{N B}<0.8\right.$, $n=\{9,29\}$ ), analogous to figures 8,9 and 10 in section 3.3. The corresponding lines drawn for the same prior are quite similar, therefore we conclude that any reduction in interest rate inertia under unanimous voting rule is mainly due to interaction and not asymmetric skills. ${ }^{14}$

\footnotetext{
${ }^{14}$ The effects of assuming that Board members are relatively less skilled than other members of the Committee are qualitatively the same.
} 


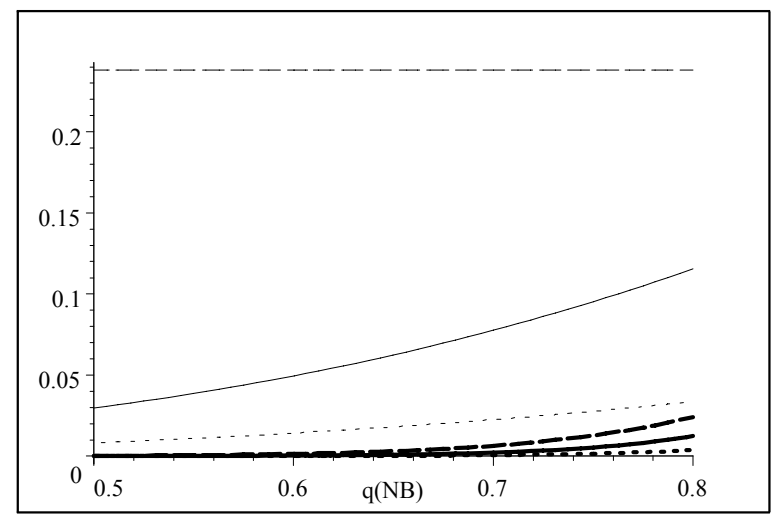

Figure 15: Expected probability of interest rate change under unanimity $\left(Q=0.25, q_{N B}<q_{B}\right)$

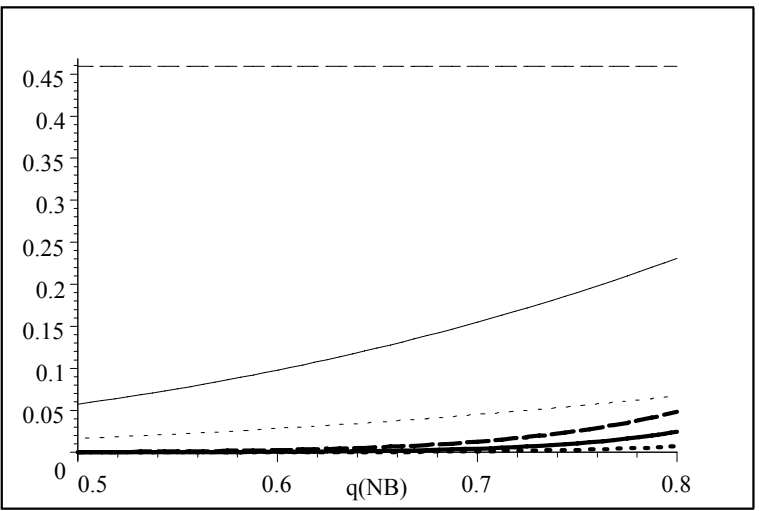

Figure 16: Expected probability of interest rate change under unanimity $\left(Q=0.5, q_{N B}<q_{B}\right)$

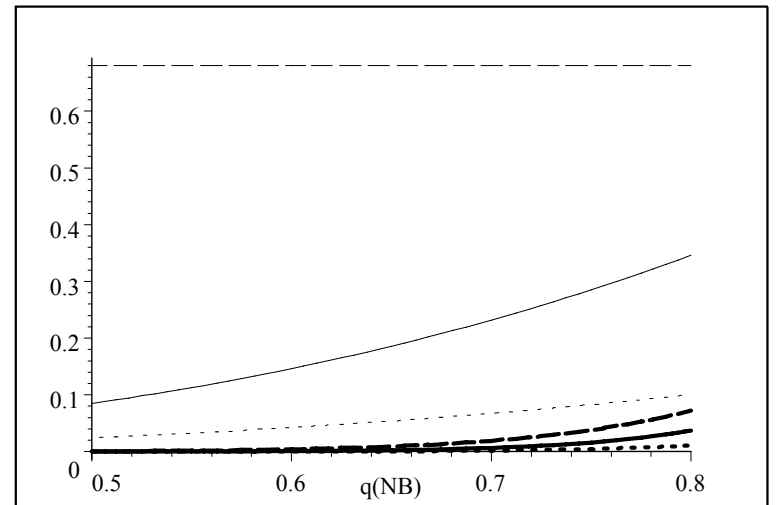

Figure 17: Expected probability of interest rate change under unanimity $\left(Q=0.75, q_{N B}<q_{B}\right)$ 


\section{Optimal size of the Committee}

We now turn to an analysis of the optimal size of the Committee, that is the size which maximizes the accuracy of its decisions (taken by simple majority), which we define as the sum of conditional expected probabilities that the Committee takes the right decision: $E P($ decision $A \mid A)$ and $E P($ decision $B \mid B)$ :

$$
\Pi=E P(\operatorname{decision} A \mid A)+E P(\operatorname{decision} B \mid B)
$$

Throughout this section we also allow for delegation of decision making to the Board. In the latter case we will assume that the decision is taken by simple majority (see formulas (7)-(8) in section 2).

When members vote individually and average decisional skills are homogeneous, the classic Condorcet Jury Theorem holds: provided that $q \geq 0.5$ and that there are no costs involved in adding Committee members, increasing the size of the Committee reduces the probability that an incorrect decision is taken. Therefore the Committee should be as large as possible: the optimum size is unbounded. As illustrated by figure 18, we retain the Condorcet result in a setting with interaction among members of the Board and when skills are homogeneous. The graph depicts values of function $\Pi$ for three Committee sizes: $n=m=6, n=19$ and $n=$ maximum $^{15}$. It follows that, for $q \geq 0.5$, the accuracy of Committee's decisions increases with its size. ${ }^{16}$ Extending interaction to the whole Committee does not affect this conclusion.

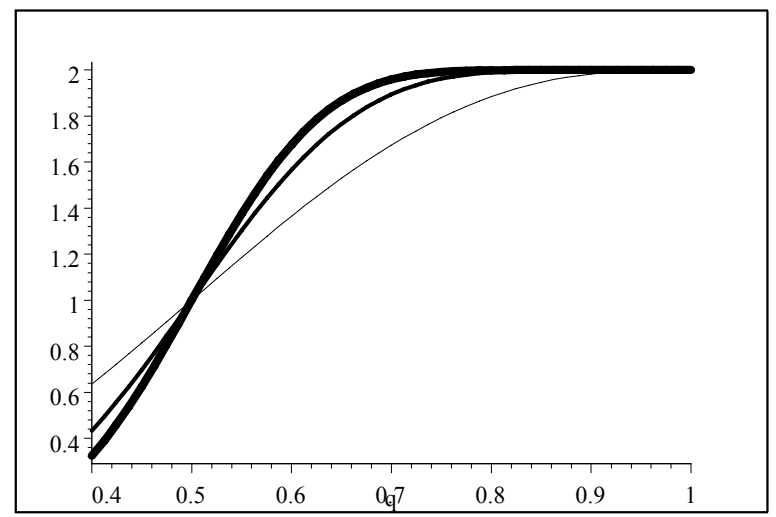

Figure 18: The accuracy of the Committee's decisions in the case of interaction (homogeneous skills)

If we introduce asymmetric skills, the Condorcet result remains basically valid: if $q_{N B}$ is below 0.5 , it is optimal to delegate decision-making to the

\footnotetext{
${ }^{15}$ In the figures the maximum is set at 29 , for presentational purposes.

${ }^{16}$ Note that, as the criterion function is bounded, it cannot exceed the value of 2 .
} 
Board; if $q_{N B}$ is large, the optimal size of the Committee is unbounded (see figures $19^{17}$ and figure $20^{18}$ ). However, the unboundedness of the optimum requires higher skill levels than in the previous case. Interestingly enough, there exists a third regime for intermediate decisional skills. In that regime the optimally-sized Committee should include a certain number of non-Board members but such that the Board retains majority. The existence of this third regime follows from the interplay between the Condorcet result and the effects of superior skills (and interaction) of Board members. ${ }^{19}$ Extending interaction within the Committee beyond the Board does not alter the qualitative results; however, since it has positive effects on the decisionmaking (see figures (11) and (12)), the range of skills in which the third regime applies becomes more limited.

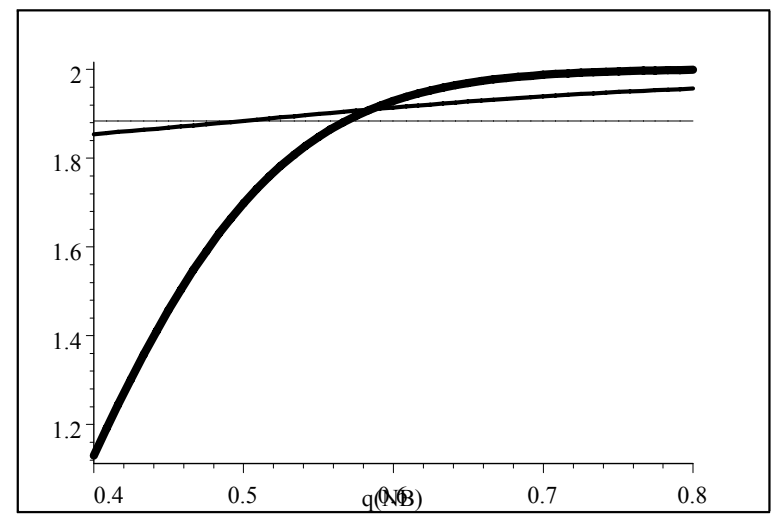

Figure 19: The accuracy of the Committee's decisions in the case of interaction (asymmetric skills)

\footnotetext{
${ }^{17}$ The thin line is drawn for $n=m=6$, the medium line for $n=11$ and the thick line for $n=29$.

${ }^{18}$ The thin line corresponds to $n=m=6$, the medium line to $n=7$ and the thick line to $n=29$.

${ }^{19}$ If we alternatively assume that non-Board members of the Committee have superior skills, then for any level of average skills among Board members, $0<q_{B}<q_{N B}$, it would be optimal to have as many non-Board members as possible, i.e. an unboundedly large Committee.
} 


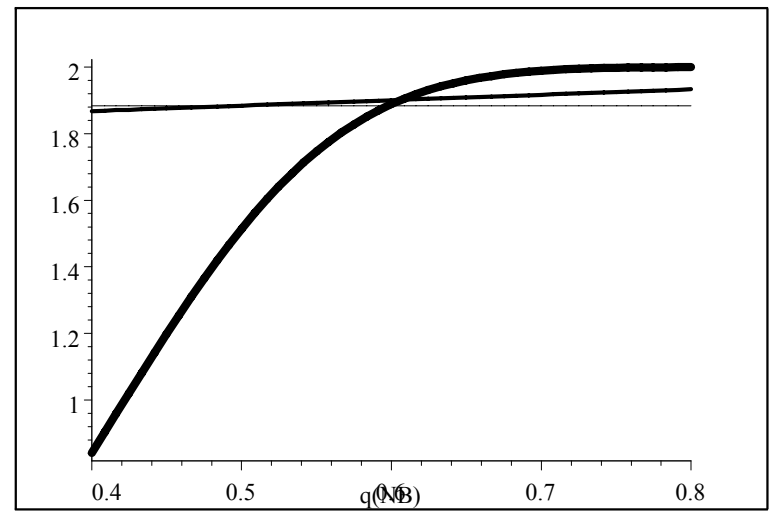

Figure 20: The accuracy of the Committee's decisions in the case of no interaction (asymmetric skills)

Investigating the case in which the Committee decides by weighted voting (i.e. the optimal rule) explains the origins of the intermediate regime: it arises as a result of an inefficient decision rule. If the rule is optimal, the Condorcet result holds without exceptions (see figure $21^{20}$ ).

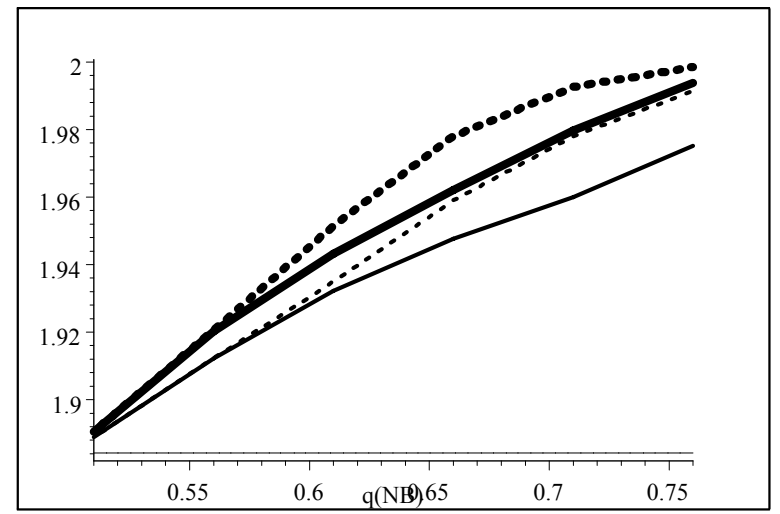

Figure 21: The accuracy of the Committee's decisions if the votes are weighted

When a certain skill level is exceeded, the optimal Committee size is unbounded. In this case, we need to introduce a cost of adding extra members. We will follow the literature (Gradstein et al. (1990)) and assume that the cost of having a Committee of $n$ members is linearly increasing in $n$ (i.e. the marginal cost of adding one extra member is constant $\left.{ }^{21}\right)$ :

$$
\begin{aligned}
C(n) & =c n \\
M C & =c
\end{aligned}
$$

\footnotetext{
${ }^{20}$ The thin line is drawn for $n=m=6$, the medium line for $n=19$ and the thick line for $n=29$. Dotted lines depict the no-interaction case, solid lines the case when Board members interact.

${ }^{21} \mathrm{~A}$ real life example of such a cost is the salary paid to each Committe member.
} 
The table below presents optimal Committee sizes as a function of decisional skills of the members (for now assumed to be identical on average) and marginal cost. In general, the lower the marginal cost of adding members, the larger the optimal size: if adding extra members is (almost) free, the optimal size of the Committee is unbounded, i.e. the Condorcet result. If on the other hand adding members is very costly, the optimal size will approach the minimum of one member. ${ }^{22}$ For a given marginal cost the optimal size decreases as the skill level increases. This is because the marginal contribution of an additional member to the accuracy of Committees composed of highly skilled individuals is lower in comparison to Committees with less skilled members.

Furthermore, the optimal Committee size differs between individual voting and interaction. For low marginal cost the optimal size of Committees in which interaction is allowed should go beyond that of Committees without interaction, ceteris paribus. This is because prior interaction results in a loss of private information if the Board assumes a common position (the information of the Board minority and those non-Board members, who follow the position of the Board), and extra non-Board members need to be added to provide additional expertise necessary to correct for this loss.

\begin{tabular}{|c|c|c|c|c|c|c|c|c|c|}
\hline & \multicolumn{3}{|c|}{ Individual voting } & \multicolumn{2}{|c|}{ Interaction } & \multicolumn{3}{|c|}{ Extended interaction } \\
\hline$M C / q$ & 0.6 & 0.7 & 0.8 & 0.6 & 0.7 & 0.8 & 0.6 & 0.7 & 0.8 \\
\hline 0.001 & $>50$ & 37 & 19 & $>50$ & 43 & 23 & $>50$ & $>50$ & 33 \\
\hline 0.002 & $>50$ & 31 & 15 & $>50$ & 37 & 19 & $>50$ & 45 & 13 \\
\hline 0.003 & $>50$ & 27 & 13 & $>50$ & 31 & 17 & $>50$ & 41 & 13 \\
\hline 0.004 & $>50$ & 23 & 13 & $>50$ & 29 & 15 & $>50$ & 37 & 13 \\
\hline 0.005 & 43 & 21 & 11 & 49 & 27 & 13 & $>50$ & 33 & 13 \\
\hline 0.006 & 37 & 21 & 11 & 43 & 25 & 13 & $>50$ & 31 & 13 \\
\hline 0.007 & 33 & 19 & 11 & 37 & 23 & 13 & 43 & 13 & 13 \\
\hline 0.008 & 29 & 17 & $<11$ & 33 & 21 & 13 & 37 & 13 & 13 \\
\hline 0.009 & 27 & 17 & $<11$ & 31 & 19 & 13 & 13 & 13 & 13 \\
\hline 0.010 & 23 & 15 & $<11$ & 27 & 19 & 13 & 13 & 13 & 13 \\
\hline 0.011 & 21 & 15 & $<11$ & 23 & 17 & 13 & 13 & 13 & 13 \\
\hline 0.012 & 19 & 15 & $<11$ & 21 & 15 & 13 & 13 & 13 & 13 \\
\hline 0.013 & 17 & 13 & $<11$ & 13 & 13 & 13 & 13 & 13 & 13 \\
\hline 0.014 & 17 & 13 & $<11$ & 13 & 13 & 13 & 13 & 13 & 13 \\
\hline 0.015 & 15 & 13 & $<11$ & 13 & 13 & 13 & 13 & 13 & 13 \\
\hline$\geq 0.016$ & $\leq 13$ & $\leq 11$ & $<11$ & 13 & 13 & 13 & 13 & 13 & 13 \\
\hline \hline
\end{tabular}

${ }^{22}$ Note that, for the case of interaction, we preclude a Board-dominated Committee, and therefore the smallest possible size is 13 . This restriction does not apply to the case of individual voting. 
If we allow for asymmetric skills ${ }^{23}$, the optimal size of the Committee is reduced, ceteris paribus. Except for very low skills of the non-Board members, the results are similar to the case of symmetric skills: if marginal cost is low, the optimum for the Committees allowing for interaction is larger than Committees which ban interaction. If the average level of skills among the non-Board members is very low, the Committees allowing for interaction are smaller.

\begin{tabular}{|c|c|c|c|c|c|c|c|c|c|}
\hline & \multicolumn{3}{|c|}{ Individual voting } & \multicolumn{3}{c|}{ Interaction } & \multicolumn{3}{c|}{ Extended interaction } \\
\hline$M C / q_{N B}$ & 0.65 & 0.7 & 0.75 & 0.65 & 0.7 & 0.75 & 0.65 & 0.7 & 0.75 \\
\hline 0.001 & $>50$ & 29 & 23 & 37 & 31 & 25 & 41 & 37 & 33 \\
\hline 0.002 & 29 & 23 & 19 & 23 & 23 & 21 & 15 & 25 & 27 \\
\hline 0.003 & $<11$ & 19 & 15 & 13 & 19 & 19 & 13 & 13 & 13 \\
\hline 0.004 & $<11$ & 15 & 13 & 13 & 13 & 15 & 13 & 13 & 13 \\
\hline 0.005 & $<11$ & 13 & 13 & 13 & 13 & 13 & 13 & 13 & 13 \\
\hline$\geq 0.006$ & $<11$ & $<11$ & $\leq 11$ & 13 & 13 & 13 & 13 & 13 & 13 \\
\hline
\end{tabular}

However, the general conclusion remains, that for the same marginal cost and skill levels, Committees should be larger if interaction is a part of the decision-making process. This result stems from inefficiencies inherent to interaction.

\section{Conclusions}

Our results have interesting implications for actual monetary policy making, when conducted in a committee. First of all, although decision-making by a committee is often associated with inertia, our analysis shows that this is by no means necessary. In fact, the size of the committee is far less important than the skills of its members in determining inertia (under a simple majority voting rule). Indeed, larger committees may be beneficial in that the accuracy of monetary policy decisions (measured as the convergence of the probability of the actual interest rate decision to the theoretical best decision) is increasing in committee size. Second, our finding that the skills of committee members are crucial in determining the quality of monetary policy decision making stresses the importance of professional reputation in monetary policy matters as selection criterion for committee membership. Given the political dimension that often surrounds appointments to monetary policy committees, this point is worth emphasizing. Third, decisional skills of committee members are defined as the ability to identify correctly

\footnotetext{
${ }^{23}$ However, we assume that the members' votes are not weighted.
} 
the monetary policy stance that is appropriate given the prevailing economic situation. This definition illustrates that the quality of the staff supporting each committee member, and of the information they base their advice on, will be instrumental in ensuring high skills of all individual committee members, both from the 'hub' and from the 'spokes'. Fourth, under a simple majority voting rule, equal level of skills between the 'hub' and the 'spokes' ensures that prior interaction does not materially affect the interest rate setting in the committee. Conversely, when the committee decides on interest rates by consensus, prior interaction will improve the outcome, even if skills are equal. Finally, the US FOMC and the ECB Governing Council differ regarding in the degree of centralization: in the FOMC, the 'hub' has the majority in the committee, in the ECB Governing Council the majority lies with the 'spokes'. Our results show that FOMC structure is superior in terms of quality of decision-making if decisional skills are asymmetric and the 'hub' has a relatively large advantage. The ECB structure, on the other hand, is superior when skills of decision-makers are relatively similar.

We would like to conclude by stating that, while the main motivation of this research is based on real life, i.e. the 'hub-and-spokes' monetary policy committees of the US Federal Reserve and the ECB, our analysis is highly stylized and contains some important caveats. This should be kept in mind when interpreting our results. An example of such a caveat is that our setup allows only for a limited and specific form of interaction among members, reducing the scope for an exchange of arguments that would lead to a change of position. As noted by others, see, for example, DNB (2000) and Goodfriend (1999), this interaction, where a common vision on interest rates evolves from an exchange of views based on economic analysis, is an important characteristic of monetary policy decision making by real-life committees such as the ECB Governing Council or the FOMC of the Federal Reserve. Our results on interaction imply that it in general reduces the quality of collective decision making, which corroborates the findings of Nitzan and Paroush (1985). However, other studies that allow for interaction among committee members (for example Swank and Wrasai (2002)) find that a debate in the committee can be beneficial. We therefore conclude that further research is warranted on this topic. Moreover, in our simple setup the only value added the board can provide is in terms of improving the quality of decision-making in the committee. This is clearly a simplification of reality, where - as mentioned in the introduction - 'hub-and-spokes' committees tend to be motivated by other arguments. Other important caveats include the static nature of our analysis, which clearly is at odds with the fact that monetary policy decisions are taken on a regular basis, so that the intertemporal dimension may be relevant for the current setting of interest rates. We plan to take up the 
latter issue in future research.

\section{Appendix 1: Position of the Board}

By Arrow's Impossibility Theorem, there is no consistent rule, majority voting or otherwise, for constructing social preferences from arbitrary individual preferences when individuals have to choose between more than two alternatives. Therefore there does not exist an optimal decision rule in such a case as ours - the choice between decision $A$, decision $B$ or no decision. Nevertheless, we can still compare different decision rules in terms of their accuracy. This appendix compares the performance of our assumed voting rule for the Board (formalized in (4)-(6)) with simple majority (formulas (7)-(9)). Our criterion is the degree of accuracy in the decisions of the whole Committee, defined as the sum of conditional expected probabilities that the Committee takes the right decision: $E P($ decision $A \mid A)$ and $E P($ decision $B \mid B)$.

$$
\Pi=P(\text { decision } A \mid A)+P(\text { decision } B \mid B)
$$

Let us proceed in two cases: the case when the Board has the majority in the Committee and the case when it does not. ${ }^{24}$

Case 1: The Board has the majority in the Committee $(n \leq 11)$

In this case the Committee's decisions are driven by the Board. Therefore the criterion function for the simple majority decision rule is given as follows:

$$
\Pi(S M)=1-\sum_{s=4}^{6}\left(\begin{array}{l}
6 \\
s
\end{array}\right)(1-q)^{s} q^{6-s}+\sum_{s=4}^{6}\left(\begin{array}{l}
6 \\
s
\end{array}\right)(1-q)^{6-s} q^{s}
$$

whereas for our decision rule, the 'modified majority', which allows for an ex-post individual voting, it is:

$$
\begin{aligned}
\Pi(M M)= & 1-\sum_{s=4}^{6}\left(\begin{array}{l}
6 \\
s
\end{array}\right)(1-q)^{s} q^{6-s}+\sum_{s=4}^{6}\left(\begin{array}{l}
6 \\
s
\end{array}\right) q^{s}(1-q)^{6-s} \\
& +\left(\begin{array}{l}
6 \\
3
\end{array}\right)(1-q)^{3} q^{3}\left(\sum_{s=\frac{n+1}{2}-3}^{n-6}\left(\begin{array}{c}
n-6 \\
s
\end{array}\right)\left(q^{s}(1-q)^{n-6-s}-(1-q)^{s} q^{n-6-\beta} \beta \delta\right)\right.
\end{aligned}
$$

In figure $1 \mathrm{~A}$ we present values of the criterion function $\Pi$ for the simple majority rule (the dotted line) and our decision rule (the solid line) for $n=9$, $m=6$ and $k_{B}=4$.

\footnotetext{
${ }^{24}$ For the sake of simplicity we assume identical decisional skills for all Committee members, $q_{B}=q_{N B}=q \geq 0.5$.
} 


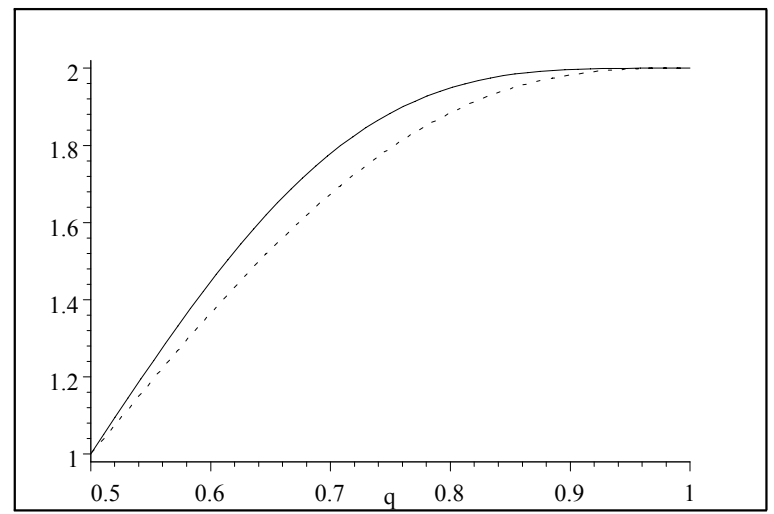

Figure 1A: The criterion function $\Pi=P($ decision $A \mid A)+P(\operatorname{decision} B \mid B)$

It is clear that our decision rule yields superior results for high decisional skills of Committee members $(q \geq 0.5)$. Let us now turn to a more complicated case of a large Committee.

Case 2: The Board is in minority (i.e. $n>11$ )

In this case the position of the non-Board members matters for the final decision. The criterion function for the simple majority decision rule is given as:

$$
\begin{aligned}
\Pi(S M)= & 1-\left[\left(1-\sum_{s=4}^{6}\left(\begin{array}{l}
6 \\
s
\end{array}\right)(1-q)^{s} q^{6-s}\right)\left(\sum_{s=\frac{n+1}{2}}^{n-6}\left(\begin{array}{c}
n-6 \\
s
\end{array}\right)(1-q)^{s} q^{n-6-s}\right)\right. \\
& \left.+\left(\sum_{s=4}^{6}\left(\begin{array}{l}
6 \\
s
\end{array}\right)(1-q)^{s} q^{6-s}\right)\left(\sum_{s=\frac{n+1}{2}-6}^{n-6}\left(\begin{array}{c}
n-6 \\
s
\end{array}\right)(1-q)^{s} q^{n-6-s}\right)\right] \\
& +\left(1-\sum_{s=4}\left(\begin{array}{l}
6 \\
s
\end{array}\right) q^{s}(1-q)^{6-s}\right)\left(\sum_{s=\frac{n+1}{2}}^{n-6}\left(\begin{array}{c}
n-6 \\
s
\end{array}\right) q^{s}(1-q)^{n-6-s}\right) \\
& +\left(\sum_{s=4}^{6}\left(\begin{array}{l}
6 \\
s
\end{array}\right)(1-q)^{6-s} q^{s}\right)\left(\sum_{s=\frac{n+1}{2}-6}^{n-6}\left(\begin{array}{c}
n-6 \\
s
\end{array}\right) q^{s}(1-q)^{n-6-s}\right)
\end{aligned}
$$


whereas for the decision rule we suggest it is:

$$
\begin{aligned}
\Pi(M M)= & 1-\left[\left(\sum_{s=4}^{6}\left(\begin{array}{l}
6 \\
s
\end{array}\right)(1-q)^{6-s} q^{s}\right)\left(\sum_{s=\frac{n+1}{2}}^{n-6}\left(\begin{array}{c}
n-6 \\
s
\end{array}\right)(1-q)^{s} q^{n-6-s}\right)\right. \\
& \left.+\left(\sum_{s=4}^{6}\left(\begin{array}{l}
6 \\
s
\end{array}\right)(1-q)^{s} q^{6-s}\right)\left(\sum_{s=\frac{n+1}{2}-6}^{n-6}\left(\begin{array}{c}
n-6 \\
s
\end{array}\right)(1-q)^{s} q^{n-6-s}\right)\right] \\
& +\left(\sum_{s=4}^{6}\left(\begin{array}{l}
6 \\
s
\end{array}\right)(1-q)^{s} q^{6-s}\right)\left(\sum_{s=\frac{n+1}{2}}^{n-6}\left(\begin{array}{c}
n-6 \\
s
\end{array}\right) q^{s}(1-q)^{n-6-s}\right) \\
& +\left(\sum_{s=4}^{6}\left(\begin{array}{l}
6 \\
s
\end{array}\right)(1-q)^{6-s} q^{s}\right)\left(\sum_{s=\frac{n+1}{2}-6}^{n-6}\left(\begin{array}{c}
n-6 \\
s
\end{array}\right) q^{s}(1-q)^{n-6-s}\right) \\
& +\left(\begin{array}{l}
6 \\
3
\end{array}\right)(1-q)^{3} q^{3}\left(\sum_{s=\frac{n+1}{2}-3}^{n-6}\left(\begin{array}{c}
n-6 \\
s
\end{array}\right)\left(q^{s}(1-q)^{n-6-s}-(1-q)^{s} q^{n-6-\beta}\right\rangle\right)
\end{aligned}
$$

In figure $2 \mathrm{~A}$ we again present the criterion function. We set $n=29$.

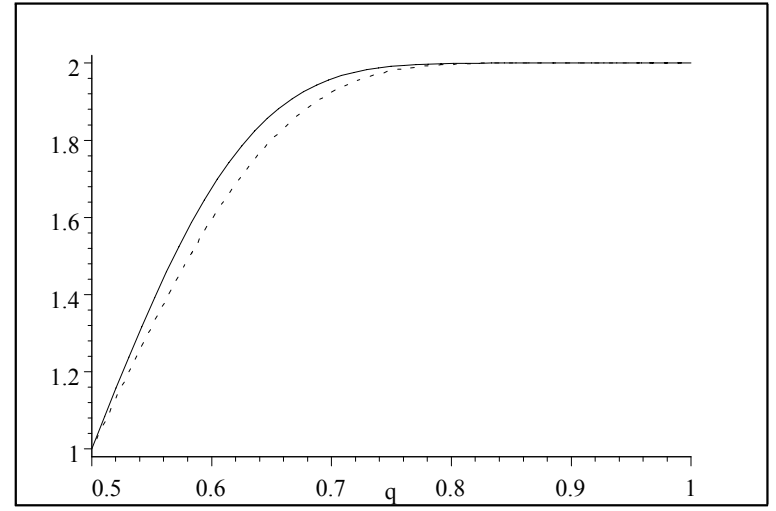

Figure 2A: The criterion function $\Pi=P($ decision $A \mid A)+P($ decision $B \mid B)$

Although the difference is much smaller now and is restricted to intermediate skill levels, our decision rule still performs better than the ordinary simple majority. We therefore claim, that the Board should be in favour of the decision rule we suggest versus ordinary simple majority.

\section{Appendix 2: Voting rules}

We mainly use either a simple majority rule or the unanimity principle when the Committee decides on interest rates. The motivation for these rules is 
mainly their real-life applicability. The FOMC for example uses a simple majority rule, whereas the Governing Council of the ECB - although de jure also supposed to use a simple majority rule - de facto sets interest rates based on the principle of consensus. ${ }^{25}$ In this appendix, we broaden the perspective by turning to a rule that is optimal in the sense that it maximizes the degree of accuracy of the collective decision-making process.

Interaction between Board members in our setup has no influence on an ex ante defined optimal voting rule, as (1) the non-Board members are not aware of the outcome of the Board's meeting, (2) the Committee vote on interest rates is simultaneous and finally (3) there is no scope for strategic considerations. As a result, the optimal rule derived by Ben-Yashar and Nitzan (1997) applies, both for individual voting and for interaction limited to the Board, under both symmetric and asymmetric skills. (The consequences for the optimal rule of extending interaction beyond the Board will be taken up in subsequent research.)

By Theorem 3.1 in Ben-Yashar and Nitzan (1997) the optimal decisive aggregation rule for our problem is defined as:

$$
\begin{aligned}
& W+\ln \frac{Q}{1-Q} \geq 0 \Rightarrow \text { decision } A \text { should be taken } \\
& W+\ln \frac{Q}{1-Q} \leq 0 \Rightarrow \text { decision } B \text { should be taken }
\end{aligned}
$$

where $W$ denotes the sum of votes weighted according to decisional skills:

$$
\begin{aligned}
W & =\sum_{i=1}^{n} x_{i} \ln \frac{q_{i}}{1-q_{i}} \\
\text { where } & \\
x_{i} & =\left\{\begin{array}{c}
1 \text { if } i \text { supports decision } A \\
-1 \text { if } i \text { supports decision } B
\end{array}\right\}
\end{aligned}
$$

and $\ln \left(\frac{Q}{1-Q}\right)$ is the optimal bias towards one of the two possible alternatives. This bias reflects the asymmetry in the priors of the two states of the world. If we partition the Committee into two groups: group $A$ supporting a change in interest rates and group $B$ supporting status quo $\left(x_{i}=1 \Rightarrow i \in A\right.$ and $x_{i}=-1 \Rightarrow i \in B$ ) then the Committee should adopt decision $B$ only if the following condition is met:

$$
\sum_{i \in B} \ln \frac{q_{i}}{1-q_{i}} \geq \sum_{i \in A} \ln \frac{q_{i}}{1-q_{i}}+\ln \frac{Q}{1-Q}
$$

\footnotetext{
${ }^{25}$ This statement is based on public comments by the ECB President during hearings in the European Parliament in April and December 1999.
} 
It follows that, if the bias is zero (i.e. if both states of the world are equally likely) the Committee should decide to change interest rates only if more Committee members are in favour of a change than against, where individual votes should be weighted according to individual skills (higher skills imply higher weight). In other words: the decision should be taken by simple majority with weighted votes. If the optimal bias is positive (i.e. if it is more likely that the state of the world is such that interest rates should be changed), adopting status quo may require relatively more members to be in favour of status quo or having relatively more skilled members voting for status quo. Similarly, if the bias is negative, status quo may be adopted even if a smaller number of Committee members is against the change in comparison to the no-bias case.

Determining optimal weights, $\ln \frac{q_{i}}{1-q_{i}}$, when there is a systematic skill differential is complicated by the fact that the skills of individual Committee members, $q_{i}$, are unknown. We follow the logic of our setup by assuming that Board members have different (i.e. higher) average skills than nonBoard members. Within each of the two groups, individuals receive equal weights. The weights are calculated for an average level of skills within each of the groups. It can be shown that the weight calculated for the average skill level is a good (first-order) approximation of the average weight of votes of the members belonging to one of the groups:

$$
\begin{aligned}
E_{i \in M}\left(\ln \frac{q_{i}}{1-q_{i}}\right) & \simeq E_{i \in M}\left(\ln \frac{q_{B}}{1-q_{B}}+\frac{1}{q_{B}\left(1-q_{B}\right)}\left(q_{i}-q_{B}\right)\right)=\ln \frac{q_{B}}{1-q_{B}}( \\
E_{i \in N-M}\left(\ln \frac{q_{i}}{1-q_{i}}\right) & \simeq E_{i \in N-M}\left(\ln \frac{q_{N B}}{1-q_{N B}}+\frac{1}{q_{N B}\left(1-q_{N B}\right)}\left(q_{i}-q_{N B}\right)\right) \\
& =\ln \frac{q_{N B}}{1-q_{N B}}
\end{aligned}
$$

where $i \in M$ implies that $i$ is a member of the Board and $i \in N-M$ that $i$ is a non-Board member of the Committee. $q_{B}$ and $q_{N B}$ denote again average skill levels among the Board and non-Board members.

If we denote by $k_{B}$ and $k_{N B}$ the number of Board and non-Board Committee members in favour of status quo, respectively, we can express the optimal decision rule as follows:

$$
k_{B} \ln \frac{q_{B}}{1-q_{B}}+k_{N B} \ln \frac{q_{N B}}{1-q_{N B}} \geq\left(m-k_{B}\right) \ln \frac{q_{B}}{1-q_{B}}+\left(n-m-k_{N B}\right) \ln \frac{q_{N B}}{1-q_{N B}}+\ln \frac{Q}{1-Q}
$$


or $^{26}$

$$
\begin{gathered}
\alpha\left(k_{B} \ln \frac{q_{B}}{1-q_{B}}+k_{N B} \ln \frac{q_{N B}}{1-q_{N B}}\right) \geq \frac{1}{2} n+\frac{1}{2} \alpha \ln \frac{Q}{1-Q} \\
\alpha=\frac{n}{m \ln \frac{q_{B}}{1-q_{B}}+(n-m) \ln \frac{q_{N B}}{1-q_{N B}}}
\end{gathered}
$$

The optimal decision rule, as formalized by (48), is to change interest rates if the number of votes in favour of a change exceeds $\frac{1}{2} n$ plus the bias, where the votes of the decision-makers have to be weighted using the formula:

$$
\begin{aligned}
w_{i, i \in M} & =\alpha \ln \frac{q_{B}}{1-q_{B}} \\
w_{i, i \in N-M} & =\alpha \ln \frac{q_{N B}}{1-q_{N B}}
\end{aligned}
$$

In figure $3 \mathrm{~A}$ below we present graphically the size of the optimal bias scaled by parameter $\alpha$, i.e. the ratio of the number of Committee members $(n)$ to the effective number of votes $\left(m \ln \frac{q_{B}}{1-q_{B}}+(n-m) \ln \frac{q_{N B}}{1-q_{N B}}\right)$, as a function of average decisional skills among the non-Board members, $q_{N B}$. We assume $q_{B}=0.8>q_{N B}, n=\{9,19\}$ and $Q=0.75 .{ }^{27}$

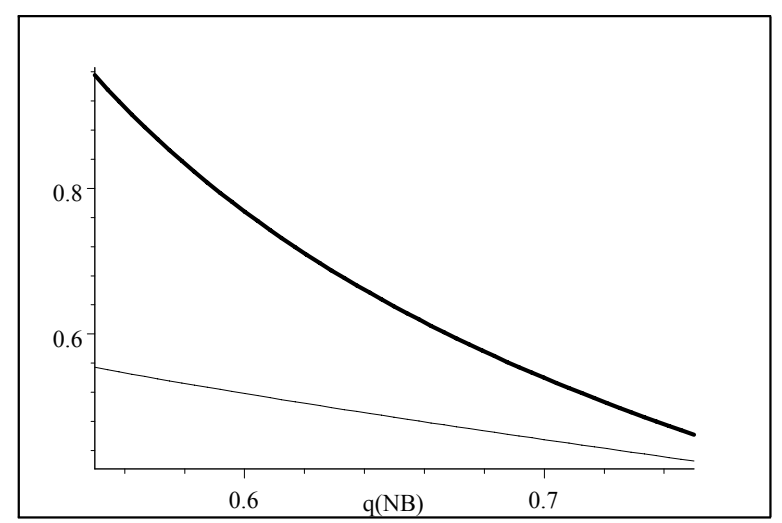

Figure 3A: The size of the optimal bias $(Q=0.75)$

Upon examining the graph we can conclude that simple majority is a reasonable approximation to the optimal decision rule since the optimal bias is likely to be small, especially if the number of Committee members is small and/or their decisional skills are high. Simple majority is furthermore more practical, since it is independent of the prior, which means the same voting rule can be used repeatedly. Conversely, the optimal rule would be different as $Q$ changes. The latter is likely to be the case over time.

\footnotetext{
${ }^{26}$ If we would approximate the optimal decision rule using the overall average of decisional skills among all Committe members, $q$, formula (48) would read: $k_{B}+k_{N B} \geq$ $\frac{1}{2} n+\frac{1}{2} \alpha \ln \frac{Q}{1-Q}$, where $\alpha=\frac{1}{\ln \frac{q}{1-q}}$.

${ }^{27}$ For $Q=0.25$ the bias is the same in magnitude but of the opposite sign.
} 


\section{References}

1. "The role of national central bank in the single European monetary policy", Quarterly Bulletin, De Nederlandsche Bank, March 2000

2. Austen-Smith D. and J.S. Banks "Information Aggregation, Rationality, and the Condorcet Jury Theorem", American Political Science Review, Vol. 90, No. 1, March 1996

3. Belden S. "Policy Preferences of FOMC Members as Revealed by Dissenting Votes", Journal of Money, Credit, and Banking, Vol. 21, No. 4, November 1989

4. Ben-Yashar R.C. and S.I. Nitzan "The optimal decision rule for fixedsize committees in dichotomous choice situations: the general result", International Economic Review, Vol. 38, No. 1, February 1997

5. Blinder A.S. "Central banking in theory and practise", MIT Press, 1998

6. Gildea J.A. "The Regional Representation of Federal Reserve Banks Presidents", Journal of Money, Credit, and Banking, Vol. 24, No. 2, May 1992

7. Goodfriend M. "The role of a regional bank in a system of central banks", Federal Reserve Bank of Richmond Working Paper No. 99-4, July 1999

8. Meade E.E. and D.N. Sheets "Regional Influences on U.S. Monetary Policy: Some Implications for Europe?", International Finance Discussion Paper No. 721, Board of Governors of the Federal Reserve System, February 2002

9. Nitzan S. and J. Paroush "Collective Decision Making. An Economic Outlook", Cambridge University Press, 1985

10. Swank O. and P. Wrasai "Deliberation, Information Aggregation and Collective Decision Making", Tinbergen Institute Discussion Paper TI 2002-006/1, 2002 